\title{
Arsenic removal from groundwater by capacitive deionization (CDI): findings of laboratory studies with model water
}

\author{
E.E. Cañas Kurz ${ }^{1}$, V.T. Luong ${ }^{2}$, U. Hellriegel ${ }^{1}$, J. Hoinkis ${ }^{3}$ \& J. Bundschuh ${ }^{2}$ \\ ${ }^{1}$ Center of Applied Research, Karlsruhe University of Applied Sciences, Karlsruhe, Germany \\ ${ }^{2}$ Faculty of Health, Engineering and Sciences, University of Southern Queensland, Toowoomba, QLD, Australia \\ ${ }^{3}$ Department of Mechatronics and Sensor Systems Technology, Vietnamese-German University, \\ Binh Duong Province, Vietnam
}

\begin{abstract}
The water supply of many countries in Southeast Asia has significant water problems and it is being affected, amongst others, by both high salinity and high arsenic concentrations in groundwater. This study presents an overview of a laboratory study using a lab-scale membrane capacitive deionization (MCDI) unit and arsenic-spiked model water. CDI is a novel technology for the electro-chemical desalination of brackish water with low energy consumption. In addition, removal performance of co-ions $\left(\mathrm{NH}_{4}^{+} ; \mathrm{Mn}^{2+}\right)$ typically found in groundwater in the region, and that have a negative influence on other conventional arsenic removal technologies, were also studied with increasing concentrations of $\mathrm{NaCl}\left(0-2.0 \mathrm{~g} \mathrm{~L}^{-1}\right)$. Results show a high dependency of the removal efficiency of selected ions on the TDS concentration, resulting in lower adsorption rates for substances in $\mu$ g-range such as arsenic.
\end{abstract}

\section{INTRODUCTION}

\subsection{Project background}

Many countries in Southeast Asia such as Vietnam, Cambodia, Laos and Myanmar have significant water problems. The strong economic growth and social development, in connection with the growing population, increasingly exert pressure on existing water resources. The water supply of these countries is also being threatened by climate change. This includes in particular the rising sea levels and an increase in extreme weather conditions, what leads to an increased salinization of groundwater and surface water. An et al. (2014) have studied coastal ground- and surface water on $\mathrm{Cu}$ Lao Dung island in southern Vietnam and found a strong salinization of groundwater with electrical conductivities of up to $24,000 \mu \mathrm{S} \mathrm{cm}^{-1}$.

Besides salinization problems many groundwater sources here have high concentration of geogenic iron (Fe) and arsenic (As). In particular, the Red River Delta has high levels of arsenic, with concentrations up to $>600 \mu \mathrm{g} \mathrm{L}^{-1}$, which are significantly higher than those recommended by the WHO drinking water standards $\left(10 \mu \mathrm{g} \mathrm{L}^{-1}\right)$. A study of Agusa et al. (2014) has shown that a large part of the Vietnamese population is exposed to high levels of arsenic (300-600 $\left.\mu \mathrm{g} \mathrm{L}^{-1}\right)$, although sand filters are used in many households for As-removal.

\subsection{Objectives}

This study is part of the project, modular concept for sustainable desalination using capacitive deionization on the example of Vietnam (www. wakap.de). The overall objective is the development and piloting of a novel, more energy-efficient, modular combined process for the desalination of groundwater consisting of a capacitive deionization (CDI) unit and an upfront in-situ treatment by aeration to remove problematic compounds such as iron $\left(\mathrm{Fe}^{2+}\right)$ and arsenite (As(III)).

\section{EXPERIMENTAL}

\subsection{Capacitive Deionization (CDI)}

CDI is a novel desalination process in which saline water flows between two porous electrodes made of activated carbon. When a voltage is applied, salt ions are drawn to the electrodes and stored in an electrical double layers within the carbon electrodes (purification phase) (Biesheuvel et al., 2015). When the electrodes become fully charged, the polarity of the electrodes is changed and stored ions can be discharged into a brine or concentrate stream (regeneration phase). In order to enhance the desalination efficiency with increased charge efficiency and avoiding co-ion transport during the regeneration phase, ion exchange membranes (IEM) were introduced to the CDI process, now so-called MCDI (Choi et al., 2016).

\subsection{Materials and method}

A lab-scale MCDI unit has been used to pre-evaluate the removal efficiency of As, $\mathrm{Mn}$ and $\mathrm{NH}_{4}^{+}$in model water simulating the high natural concentrations seen 
Table 1. Operational parameters MCDI.

\begin{tabular}{lllrl}
\hline Phase & Cycle & $\begin{array}{l}\text { Flow } \\
\text { L min }^{-1}\end{array}$ & $\begin{array}{l}\text { Time } \\
\text { sec }\end{array}$ & $\begin{array}{l}\text { Current } \\
\text { A }\end{array}$ \\
\hline 1 & Regeneration & 0.25 & 115 & 57.6 \\
2 & Pre-purify* & 1.0 & 40 & 18.1 \\
3 & Purify & 1.0 & 310 & 18.1 \\
\hline
\end{tabular}

*Pre-phase to ensure quality in purification cycle.

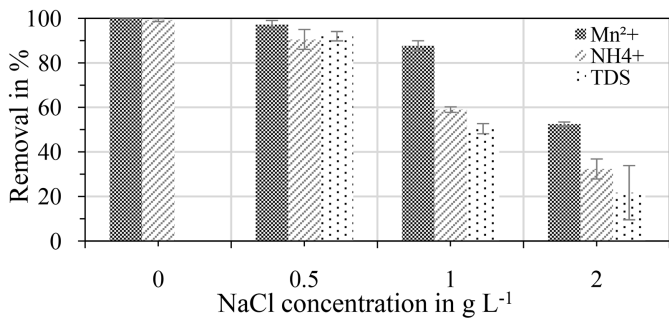

Figure 1. Removal of manganese $\left(C_{0, \mathrm{Mn}}=6 \mathrm{mg} \mathrm{L}^{-1}\right)$, ammonium $\left(C_{0}, \mathrm{NH}_{4}+=25 \mathrm{mg} \mathrm{L}^{-1}\right)$ and total dissolved solids (TDS) with respects to their initial concentrations $C_{0}$ vs. increasing initial $\mathrm{NaCl}$. Initial $\mathrm{pH}$ and temperature were $7.1 \pm 0.6$ and $25 \pm 3^{\circ} \mathrm{C}$.

in the groundwater in Vietnam. The initial TDS concentration was varied between $0 ; 0.5 ; 1.0$ and $2.0 \mathrm{~g} \mathrm{~L}^{-1}$ $\mathrm{NaCl}$. Purification and regeneration cycles were kept equal in all single-pass experiments. Table 1 shows the operational settings of the MCDI chosen based on experimentally determined configurations for a high-energy-efficient operation.

\section{RESULTS AND DISCUSSION}

\subsection{Ammonium and manganese removal}

The results (Fig. 1) show that the removal of Mn is more favorable over $\mathrm{NH}_{4}^{+}$and the overall adsorption of TDS $(\mathrm{NaCl})$, what can be explained by the higher valence state $(2+)$ of $\mathrm{Mn}$ over $\mathrm{NH}_{4}^{+}, \mathrm{Cl}^{-}$and $\mathrm{Na}^{+}$.

The higher removal of $\mathrm{NH}_{4}^{+}$over the $\mathrm{NaCl}$ might be due to its smaller hydrated ion radius, which allows a higher ion mobility and increased diffusion towards the electrodes and through the IEM. Moreover, with increasing $\mathrm{NaCl}$ concentrations, the removal efficiency for selected ions drops as more ions compete for adsorption places and the electrodes become saturated more rapidly. This behavior is in accordance with previous studies (Fan et al., 2016).

\subsection{Arsenic removal}

Adsorption experiments for different $\mathrm{As}(\mathrm{V})$ concentrations $\left(50-200 \mu \mathrm{g} \mathrm{L}^{-1}\right)$ are shown in Figure 2. Results show that for the given low concentrations of arsenic $(\mu \mathrm{g})$ the selective arsenic removal with MCDI, even with $\mathrm{NaCl}$ concentrations as low as $0.5 \mathrm{~g} \mathrm{~L}^{-1}$, was very

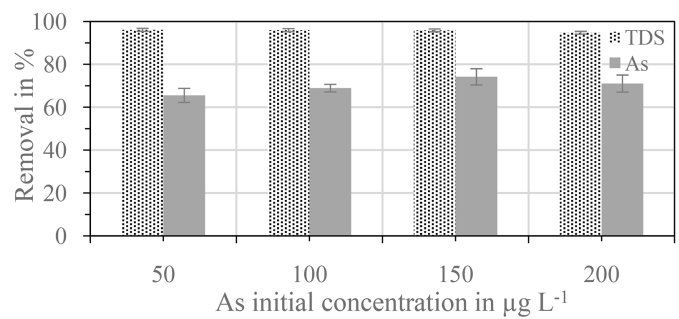

Figure 2. Removal of arsenic with MCDI (TDS $=$ $0.5 \mathrm{~g} \mathrm{~L}^{-1}$ ). Initial $\mathrm{pH}=6.5 \pm 0.5$ and $\mathrm{T}=18 \pm 0.2^{\circ} \mathrm{C}$.

limited. An average max. As-removal of only $70 \pm 3 \%$ was achieved, so that complying with drinking water standard of $10 \mu \mathrm{g} \mathrm{As} \mathrm{L}^{-1}$ was not possible under given conditions. Salt removal was stable at $96 \pm 1 \%$.

Low As-removal can be mainly explained by the energy-efficient operational settings chosen as well as the extreme low As-concentrations, which makes the selective As-elimination with MCDI, when dissolved salts are present, challenging.

\section{CONCLUSIONS}

The decrease in the removal capacity with increasing TDS concentrations can be attributed to the electrosorbtion competition by $\mathrm{Na}^{+}$and $\mathrm{Cl}^{-}$-ions. In order to improve removal efficiency at higher TDS, higher currents (increased energy consumption) and shorter purify phases (lower recovery) should be considered.

\section{ACKNOWLEDGEMENTS}

The project was funded by the German Federal Ministry of Education and Research (BMBF) under the grant number 02WAV1413A.

\section{REFERENCES}

Agusa, T., Trang, P.T.K., Lan, V.M., Anh, D.H., Tanabe, S., Viet, P.H. \& Berg, M. 2014. Human exposure to arsenic from drinking water in Vietnam. Sci. Total Environ. 488489: 562-569.

An, T.D., Tsujimura, M., Le Phu, V., Kawachi, A. \& Ha, D.T. 2014. Chemical characteristics of surface water and groundwater in coastal watershed, Mekong Delta, Vietnam. Procedia Environ. Sci. 20: 712-721.

Biesheuvel, P.M., Hamelers, H. \& Suss, M.E. 2015. Theory of water desalination by porous electrodes with immobile chemical charge. Colloid. Interface Sci. Commun. 9: 1-5.

Choi, J., Lee, H. \& Hong, S. 2016. Capacitive deionization (CDI) integrated with monovalent cation selective membrane for producing divalent cation-rich solution. Desalination 400: 38-46.

Fan, C.-S., Liou, S.Y.H. \& Hou, C.-H. 2016. Capacitive deionization of arsenic-contaminated groundwater in a single-pass mode. Chemosphere 184: 924-931. 